\title{
A Study for Optimizing the Management Strategies of a Hybrid Photovoltaic-Diesel Power Generation System
}

\author{
M. Sylos Labini ${ }^{1}$, G. Delvecchio ${ }^{2}$, M. Guerra ${ }^{3}$, C. Lofrumento ${ }^{1}$ and F. Neri ${ }^{1}$ \\ ${ }^{1}$ Department of Electrotechnics and Electronics - Polytechnic of Bari \\ Via E. Orabona 4 - 70125 Bari (Italy) \\ phone: +39080 5963256, fax: +39080 5963410, e-mail: sylos@poliba.it \\ ${ }^{2}$ Technical Area - University of Bari \\ Piazza Umberto I n.1 , 70100 Bari (Italy) \\ phone:+39 080 5714648, fax:+39 080 5714655, e-mail: g.delvecchio@area-tecnica.uniba.it \\ ${ }^{3}$ ENEA - Experimental Area Monte Aquilone \\ SS $89 \mathrm{~km} 178+700,71043$ Manfredonia FG (Italy) \\ phone: +390884 543493, fax: +390884 543940, e-mail: michele.guerra@portici.enea.it
}

\begin{abstract}
In this paper the Authors, on the basis of a software for the management of the hybrid systems, optimize the performance of a real plant under different working conditions. The plant under examination is called Delphos and is a solar installation of ENEA (National Agency of Alternative Energy) in the South of Italy.
\end{abstract}

Key words: hybrid systems, optimization,

\section{Introduction}

It's worthy that, in the hybrid systems for the autonomous generation, if the assembly of generation, conversion and storage devices gives the possibility of exploiting at best the availability of local renewable energy sources, on the other hand it involves a shrewd choice of the typologies of these devices, this choice having to be made a priori in order to realize high reliability and low costs. This problem is even more important if we take into account that, generated powers being equal, the cost of photovoltaic generators, wind turbines and batteries is clearly higher than the cost of traditional generators fed by fossil. Moreover, as is wellknown, a good operation of a hybrid system can be achieved only by a suitable control of the interaction in the operation of the different devices. An exhaustive knowledge of the management strategies to be chosen in the preliminary stage is therefore fundamental to optimize the use of the renewable sources, minimize the wear of batteries, consume the smaller possible quantity of fossil fuel [1], [2].

The study has been made on a real plant and various simulations have been carried out by a software for optimizing the management of the backup (i.e. the diesel generator) and storage (i.e. the battery) devices.

Backup and storage devices are therefore at the centre of this study. These devices ensure that the system has a very useful store of energy, even if they make the whole plant no more environmentally compatible because of the quality of the diesel emissions and the recycling capacity of the battery when it has gone flat.

\section{The system under examination}

The system under study is a photovoltaic system called Delphos (Demonstrative Electrical Photovoltaic System) ENEA. It is a solar installation of the National Agency of Alternative Energy (ENEA) which is near the experimental area of Monte Aquilone in the South of Italy. The plant under examination has a total installed capacity of $600 \mathrm{kWp}$.

It is among the 25 most important plants in order of power in Europe. It consists of 2 sections, each having $300 \mathrm{kWp}$, and can supply an annual average production of about $450 \mathrm{MWh}$. It has been in operation since 1986 when the first $300 \mathrm{kWp}$ generator came into service. A second $300 \mathrm{kWp}$ section was completed in 1992. The latter includes three standard $100 \mathrm{kWp}$ plants, known as PLUGs, (Photovoltaic Low-cost Utility Generators).

The section devoted to the hybrid plant is based on both a $50 \mathrm{kWp}$ photovoltaic source and an asynchronous generator driven by a diesel engine. The internal energy storage is assured by lead-acid batteries. The system management is performed by means of an energy manager called TEMA, which is made up of modern high-efficiency solid state switching converters [3].

Fig. 1 gives a schema of all the components of the hybrid plant. The main nominal specifications for the plant devices are reported in Tables I and II.

TABLE I

\begin{tabular}{|c|c|}
\hline \multicolumn{2}{|c|}{$\begin{array}{l}\text { SPECIFICATIONS OF PV FIELD AND ENERGY } \\
\text { STORAGE }\end{array}$} \\
\hline $\begin{array}{l}\text { Photovoltaic } \\
\text { field }\end{array}$ & $\begin{array}{l}\text { @ STC: } \mathrm{Voc}=600 \mathrm{~V} ; \mathrm{Pmpp}=50 \mathrm{~kW} ; \mathrm{Vmpp}= \\
460 \mathrm{~V} ; \mathrm{Impp}=108 \mathrm{~A}\end{array}$ \\
\hline $\begin{array}{l}\text { Charge } \\
\text { regulator }\end{array}$ & $\begin{array}{l}\text { Boost converter topology, Iin } \max =210 \mathrm{~A}, \\
\text { Pmax }=50 \mathrm{~kW}\end{array}$ \\
\hline Battery & $\begin{array}{l}\text { Lead-Acid battery, nominal voltage }=500 \mathrm{~V}, \\
\text { minimum voltage }=450 \mathrm{~V}, \text { max. discharge } \\
\text { current }=100 \mathrm{~A}, \\
\text { max } . \text { charge current }=69 \mathrm{~A}, \text { Nominal battery } \\
\text { capacity }: 690 \mathrm{Ah}\end{array}$ \\
\hline
\end{tabular}


TABLE II

\begin{tabular}{|l|l|}
\hline MAIN INTERNAL UNITS Specifications \\
\hline CPU Dispatcher & $\begin{array}{l}\text { Elettronica Santerno "MICROFAST" } \\
\text { controller }\end{array}$ \\
\hline Generator Inverter & $\begin{array}{l}\text { Elettronica Santerno "Sinus VTC" } \\
\text { torque control inverter } \\
\text { Pn= 50KVA, Iout= 75A } \\
\text { Overload 150\% during 15 sec }\end{array}$ \\
\hline $\begin{array}{l}\text { Grid/load Inverter } \\
\text { and transformer }\end{array}$ & $\begin{array}{l}\text { Elettronica Santerno "Sunway T" solar } \\
\text { inverter } \\
\text { Pout= 120kW, Mains voltage 400 } \\
\text { Vac } \pm 20 \%, 50 \mathrm{~Hz} \\
\text { Nominal current = 150A }\end{array}$ \\
\hline $\begin{array}{l}\text { Asynchronous } \\
\text { generator }\end{array}$ & $\begin{array}{l}50 \mathrm{~kW} \text { squirrel cage induction motor, 4 } \\
\text { poles 220/380V } \Delta / \mathrm{Y}, \\
\text { Nominal speed 1500RPM }\end{array}$ \\
\hline Endothermic engine & $\begin{array}{l}\text { "GVM" model D704LT - 2775cc four } \\
\text { stroke diesel engine 45 kW @ } \\
1500 R P M\end{array}$ \\
\hline
\end{tabular}

\section{Choice of the software}

Among the various available software the Authors have chosen the Hybrid Designer which has been carried out at the Energy and Development Research Centre (EDRC) of the University of Cape Town in South Africa. It is a userfriendly software that can be easily configured and, as for the managed information, it is complete, too. This software is based on a genetic algorithm that can evaluate different situations to determine the system configuration that will provide acceptable reliability at the lowest lifecycle cost [2], [4].

The user is able to choose between different sources such as photovoltaic source, wind generator, battery and diesel generator.

\section{The strategies of management}

The optimal management of a power system consisting of generators fed by alternative energy sources lies in maximizing the resource availability. As for the photovoltaic generators, when the solar energy is not used for directly supplying the loads, it should be completely stored. This turns into a high utilization rate of photovoltaic generation. Special operating conditions, such as high state of charge (SOC) of the battery and/or diesel operating with low load demand profiles, can lead the system controller to economize on the supply of the power generated by the photovoltaic generator. Moreover, if the plant has been dimensioned to comply with semi-seasonal users when the loads decrease remarkably (more than 30\%) for prolonged periods of time compared to the rated operating conditions, it is necessary to have an adequate control system.

The relation of the amount of generated energy to that which is absorbed must be accompanied by a careful evaluation of the way in which the various generation devices are used to have the maximum efficiency at the minimum cost of each device.

Different fundamental concepts and suggestions to optimize the system operation control have been carried out by many authors.

The most important strategies of management are the

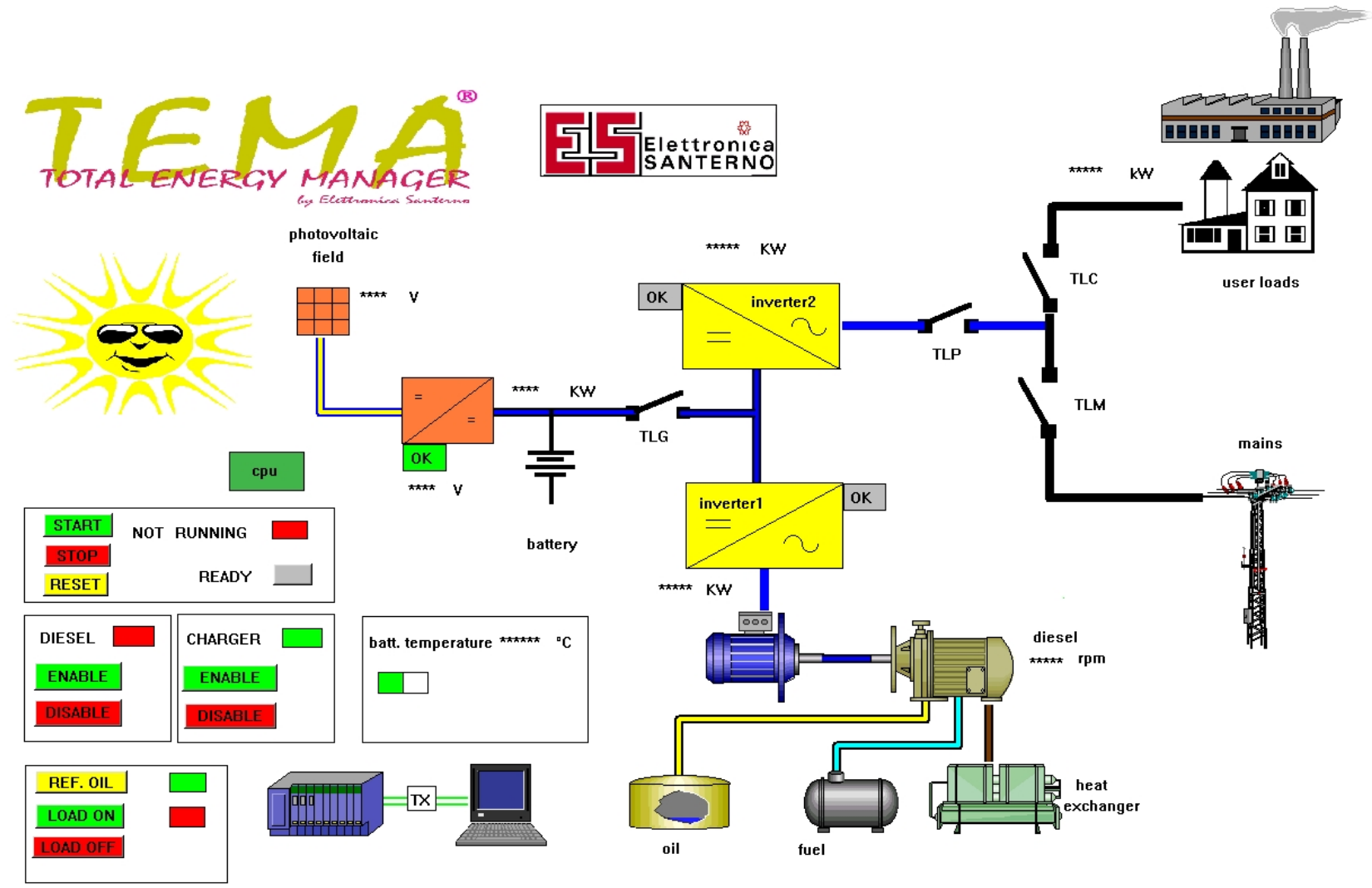

Fig.1 Synoptic table of the ENEA plant 
following [6]:

- the "battery cyclic charge", consisting in both maximizing the battery operation to feed the loads, and using the diesel for recharging it;

- the "load following strategy", consisting in using the diesel only to comply with the load, while the battery is recharged only by the photovoltaic system;

- the "diesel only to charge the battery";

- the "frugal battery discharge strategy", consisting in optimizing both the fuel consumption and the battery wear by determining the starting and stopping of the diesel generator at a certain power level.

\section{Determination of an optimal management strategy}

According to the available data, the Authors have decided to carry out the study by an examination made over a little period of time. In this way it is possible to compare the performance of the real system with the simulated one under different management strategies.

The purpose of this study is represented by both battery and diesel generator operation since they are the main elements of the efficiency of the total system performance.

The Authors have taken into account some variables which can describe the quality of the diesel operation and the battery's degradation state.

As for the diesel generator, fuel consumption, operation time and start-ups frequency, that is the rate at which start-ups happen, are considered.

As for the variables that can influence the battery operation, the current passing through the battery, the width of the battery charge and discharge cycles, and the state of charge are taken into consideration [1], [5], [6], [7].

With reference to the above-mentioned four strategies of management, the two main ones are the "battery cyclic charge strategy", that seeks to use energy from the battery to a great extent and to use, where possible, the diesel generator to charge the battery, and the "load following strategy", which doesn't use the diesel generator to charge the battery at all. The operating point of the diesel generator is set to match the instantaneous net load. We can recognize that the Delphos plant operates under this kind of strategy, where the diesel generator automatically starts when photovoltaic power generation drops and the storage batteries are unable to meet the power demand.

Our research has been done in the following way. Once a particular kind of users has been targeted, we have looked for periods of time in which the Delphos plant operates under the best reliable possible conditions, especially in the months in which the direct sun radiation is not as much as usual. With reference to these periods of time some simulations have been carried out and their results have been compared with those relating to the real system.

The optimization got by the Hybrid Designer software has led to adopt the "battery cyclic charge strategy" in which the diesel generator minimizes its hours of operation and maximizes its rated power. In fact the periodic start up of the diesel generator occurs on the average when the photovoltaic generator undergoes a decrease by more than $95 \%$. The diesel is then compelled to operate for the time needed to recharge the battery at a high power factor, about $75 \%$ of the power, and anyway the loads continue to be fed. In this way it is possible to get a remarkable saving of fuel with respect to the operation rate of the real Delphos plant where the diesel starts up working for a greater number of hours but at a power factor equal to $15 \%$ of the rated power. In fact, in the "load following strategy" the diesel covers the load peaks (as a classic backup device) not only when there is lack of sun radiation but also at night when the battery charge has not sufficiently been recharged in the daytime.

In short, the "battery cyclic charge strategy" allows the optimization of the operation rate as regards not only consumption (reduced by half) but also the hours in which it is employed, the ratio between the costs being equal to $1: 2$ (one to two).

Anyway, the use of the "diesel following strategy" in the real Delphos plant allows a smaller wear of the battery, and so a greater working life.

Fig. 2 shows the trend of the battery state of charge (SOC) and the trend of the battery current in the case of both real plant ("load following strategy") and simulated plant ("battery cyclic charge strategy").

\section{Conclusions}

The great number of simulations carried out leads to the conclusion that the "battery cyclic charge" allows a good maintenance of the state of charge of the battery and a specific saving of fuel, with respect to the working state of the real system ("load following strategy"). Anyway, the real system allows a smaller wear of the battery and so a greater working life.

The comparison of the two above strategies of management has also shown a higher cost of maintenance of the simulated system compared to the real system because of the cyclic periods of battery recharging.

The simulations carried out have confirmed the close interdependence of management choices and climatic conditions.

In conclusion, for the hybrid systems to be adapted to the different environmental needs, it is necessary to rely on a robust simulation software. In this way it is possible to make the most suitable choices to the advantage of the communities being in need of an autonomous generation system. 


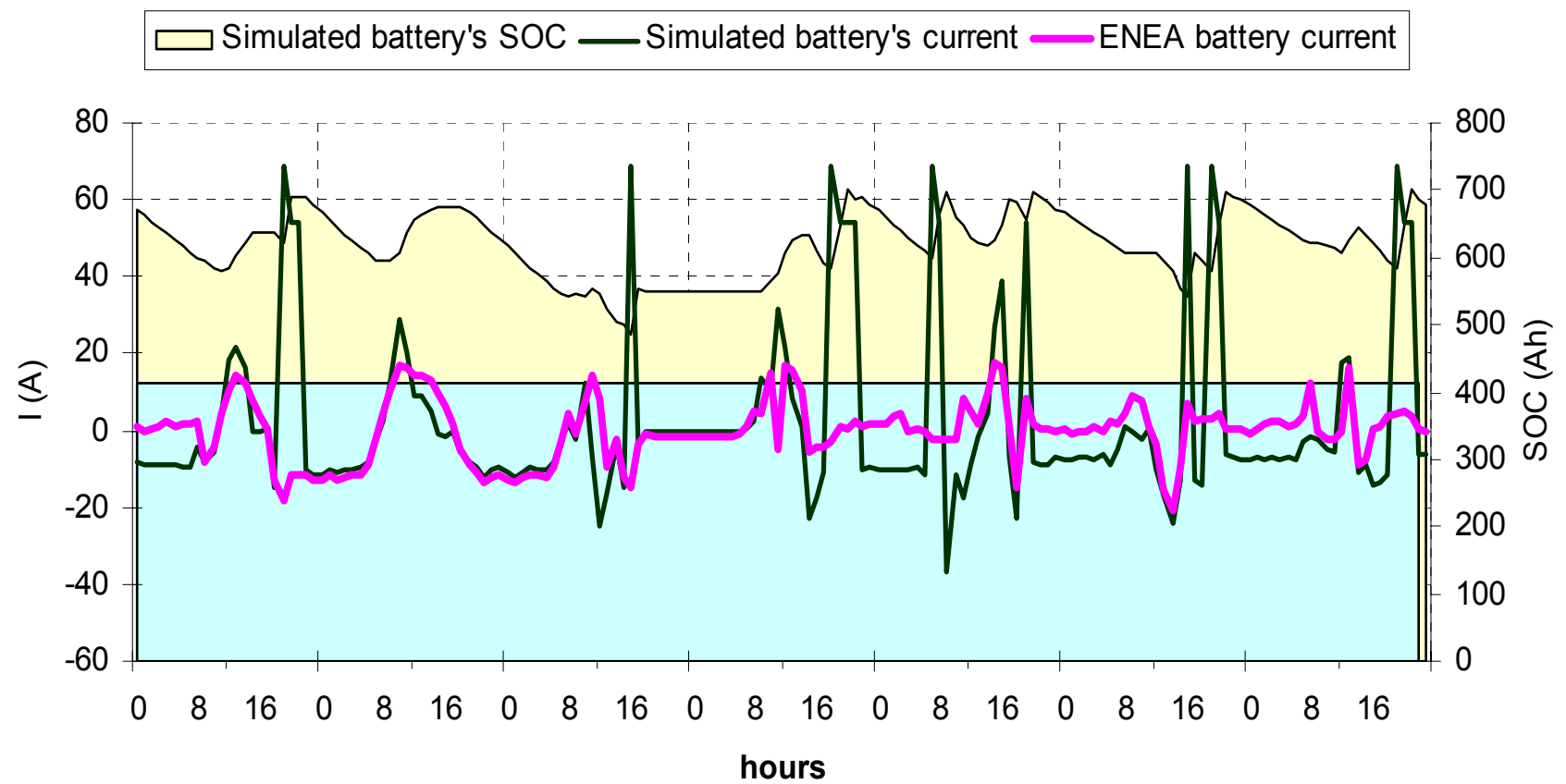

Fig. 2 Trend of the battery SOC and current in the case of both real plant and simulated plant

\section{References}

[1] G. Seeling-Hochmuth, "A Combined Optimization Concept for the Design and Operation Strategy of Hybrid PV Energy Systems", Solar Energy, Vol. 61, No. 2, pp. 77-87, Elsevier Science Ltd, 1997.

[2] G. C. Seeling, "Optimization Of PV-Hybrid Energy System Design And System Operation Control Using Genetic Algorithms", in Proc. of the 13th EC PV Conference, Nice, France, pp. 4, 1995.

[3] A. Sarno, S. Castello, S. Cordisco, M. Guerra, "ENEA experience in managing PV plants installed and operating in different locations", in Proc. of the 14th European Photovoltaic Solar Energy Conference, Barcelona, Spain, July 1997.

[4] D. Turcotte, M. Ross, F. Sheriff, "Photovoltaic hybrid system sizing and simulation tools: status and needs, in PV Horizon", Workshop on Photovoltaic Hybrid Systems, Montreal, September 10, 2001.

[5] T. D. Hund, S. Gates, "PV hybrid system and battery test results from Grasmere Idaho", in the 29th IEEE Photovoltaic Specialists Conference, New Orleans, May 2002.

[6] M. Ibrahim, Decentralized hybrid renewable energy system, Ph. D thesis, Kassel University, Germany, May 2002

[7] W. Kleinkauf, M. Ibrahim, O. Haas and B. Gruß, "Basics of Hybrid Technology for Grid Compatible Stand-Alone Plants".

[8] M. Asaoka S. Sakata, "A Hybrid Photovoltaic-Diesel Power Generation System for Miyako Island", Mitsubishi Electric advance, technical report, pp. 9-11, September 1997. 